\title{
Prevalence and factors associated with group B streptococcal colonization in pregnant women
}

Taís Viana Lédo de Oliveira 1

https://orcid.org/0000-0002-6507-5842

Fabrícia Almeida Fernandes Santana 2

iD https://orcid.org/0000-0002-2797-2104

Claudio Lima Souza 3

https://orcid.org/0000-0002-8094-8357

Márcio Vasconcelos Oliveira 4

https://orcid.org/0000-0002-8959-0478

1-4 Instituto Multidisciplinar em Saúde. Universidade Federal da Bahia. Rua Rio de Contas, 58 - Quadra 17 - Lote 58, Bairro Candeias. Vitória da Conquista, BA, Brasil. CEP: 45.029-094. E-mail: tai_av@hotmail.com

\begin{abstract}
Objectives: to estimate the prevalence and the factors associated with the colonization by group B streptococcus (GBS) in pregnant women from the urban area attended at health units in a municipality in northeastern Brazil.

Methods: it is a cross-sectional study conducted from January 2017 to March 2018. Vagino-rectal swabs were collected from 210 pregnant women between 32 and 40 weeks of gestation. The swabs were seeded on 5\% sheep blood agar and on chromogenic agar. For confirmatory identification of GBS, the CAMP test and latex agglutination were used. Descriptive analysis and univariate and multivariate association analysis were performed using a multinomial logistic model.

Results: the prevalence of GBS colonization among pregnant women was $18.1 \%(n=38)$, and a statistically significant association $(p<0.05)$ was found for income and parity variables in the group of older women in the univariate analysis, and for skin color, age and parity in the final multivariate analysis.

Conclusions: the prevalence of maternal colonization by GBS was similar to that described in other studies. Although some risk factors, such as skin color, age and parity, were associated with colonization, other studies are essential to establish more information on pregnant women more likely to be colonized by GBS.
\end{abstract}

Key words Group B streptococcus, Streptococcus agalactiae, Prevalence, Pregnant women

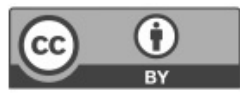




\section{Introduction}

The Group B Streptococcus (GBS) or Streptococcus agalactiae is part of the mucous membrane microbiota of humans and animals, mainly colonizing the intestinal and genitourinary tracts. ${ }^{1}$

In pregnant women, GBS is associated with infections such as cystitis, pyelonephritis and endometritis. In addition, it may be related to impairment in the evolution of pregnancy, with possible occurrence of abortion, intrauterine fetal death, chorioamnionitis and early rupture of the membrane and premature delivery. ${ }^{2}$

GBS is the main etiological agent associated with early-onset neonatal sepsis. And, among newborns of parturients colonized by GBS, 1-2\% will develop invasive disease of early onset. 3,4 These exposed newborns can develop serious illnesses, such as pneumonia, sepsis and meningitis. 5

The transmission of GBS to the newborn can occur during labor due to the ascension of the bacteria to the uterine cavity, mainly after the rupture of the amniotic membranes or by contact with maternal secretions, in the birth canal. 6

The recommended prophylactic strategy for invasive GBS disease in the neonatal period is based on specific prenatal screening for the pathogen in material collected from the vaginal opening and perianal region of women between the $35^{\text {th }}$ and 37 th weeks of gestation. In order to prevent vertical transmission of GBS, intrapartum prophylaxis is recommended, with crystalline penicillin G - 5 million units in a loading dose and 2.5 million units, every 4 hours, until delivery. ${ }^{7}$

In Brazil, there are no protocols or technical recommendations on the topic. 8,9 Although screening in pregnant women is accessible and the collection is simple, it is observed that culture for GBS is currently not routinely performed in prenatal care. 10

National studies have shown maternal colonization rates between $4.2 \%$ and $28.4 \% .11,12$ These variations follow the geographical location, including regional fluctuations. ${ }^{10}$ In addition, these findings may differ due to the anatomical site and time of collection, type of sample, bacteriological isolation technique used, and also to characteristics of the studied population. 11

Given the relevance of GBS as a cause of morbidity and mortality in newborns, in addition to knowledge of maternal prevalence of colonization and the need for implementation of preventive measures based on screening pregnant women, the adoption of prophylactic measures may contribute to the reduction of infant deaths, especially neonatal. The present study aimed to estimate the prevalence and list factors associated with the colonization of Streptococcus agalactiae isolated from pregnant women in the urban area treated at health units in Vitória da Conquista, State of Bahia.

\section{Methods}

This is a cross-sectional study with a quantitative approach carried out in the municipality of Vitória da Conquista - Bahia between February 2017 and March 2018. The sample was composed of 210 pregnant women, with gestational age of 32 to 40 weeks, attended in nine basic health units and family health units in the municipality, all located in the urban area, selected from the municipality's zoning followed by drawing lots of units by area.

To calculate the sample size, an error of $5 \%$ and a $95 \%$ confidence interval were accepted, taking into account the 5,191 births in the municipality in 2014 and the prevalence of colonization by GBS of $17 \%$, tax referred in a study performed in the municipality. 13 As to define the number of pregnant women in each health unit, the sample number was divided proportionally in the units involved in the study. Pregnant women undergoing prenatal care at the health unit with a gestational age of 32 to 40 weeks who agreed to participate after applying the Informed Consent Form (ICF) were considered eligible to participate in the study.

Data collection involved applying the selfreported questionnaire with predefined questions about possible explanatory variables for the researched outcome, except for the gestational age that was obtained by collecting ultrasound data from the pregnant woman's medical record. This questionnaire was prepared from the data sheet of the study by Borger ${ }^{14}$ and underwent pre-tests to adapt the language and maintain necessary requirements for the adequacy of the study.

The material was collected by introducing a single sterile swab into the vaginal canal, without the use of a speculum and, subsequently, from the anal sphincter, and inoculation of the swab in Stuart transport media. 7,13 The swabs were sent in boxes for biological material, at room temperature, to the Clinical Analysis Laboratory of the Federal University of Bahia - Campus Anísio Teixeira -Multidisciplinary Health Institute, Vitória da Conquista - BA.

The samples were sown in a chromogenic medium (Biomérieux ${ }^{\circledR}$ ) for streptococci by depletion technique, and incubated 18 to 24 hours at a tempe- 
rature of 35 to $37{ }^{\circ} \mathrm{C}$. Subsequently, sown on Blood agar (Isofar $\left.{ }^{\circledR}\right) 5 \%$ (lamb), with incubation from 18 to 24 hours at 35 to $37{ }^{\circ} \mathrm{C}$, and an atmosphere of $5 \%$ $\mathrm{CO}_{2}$. Following the protocol, the swab was inoculated in a tube containing Todd-Hewitt medium (Biomérieux ${ }^{\circledR}$ ) at 35 to $37{ }^{\circ} \mathrm{C}$ from 18 to $24 \mathrm{~h}$ and after that period, new sowing in chromogenic medium (Biomérieux ${ }^{\circledR}$ ) for streptococci and Blood $\operatorname{agar}\left(\operatorname{Isofar}^{\circledR}\right) 5 \%$ (lamb), following the same incubation conditions as before for these cultures. $7,13,14$

For blood agar cultures with growth of small colonies, with a grayish pattern, surrounded by a discrete halo of $\beta$-hemolysis, or without hemolysis, suggestive of GBS, catalase test and conventional Gram stain followed by microscopic analysis were performed. For Gram-positive catalase-negative coconuts obtained from growth on blood agar and for pink or red colonies obtained in a chromogenic medium, a CAMP (Christie, Atkins and MunchPetersen) test was performed, using the Todd-Hewitt and Hemolisinabac ${ }^{\circledR}$ (Brasil'sProbac) and latex agglutination (serogroup) using the Slidex ${ }^{\circledR}$ Strepto Plus B kit (Biomeriéux), to confirm the species.

To support the analyzes, the database was built on Microsoft Office Excel spreadsheets and the descriptive, univariate and multivariate statistical analyzes were performed on the EPI-INFO statistical package (version 3.5.2 and version 7.0.9).

Colonization by GBS confirmed by laboratory was considered the response variable in this study, and the following explanatory variables were evaluated: a) sociodemographic: age group, skin color, education, marital status, income; b) pathologies: report of diagnosis of any disease; c) previous pregnancy information: abortion and premature birth; d) current gestational information: gestational age, weight, use of antibiotics during pregnancy and use of other medications.

For comparison of frequencies, the chi-square test was used, adopting a significance level of $p<0.05$. For the final modeling, variables with $p<0.20$ in the univariate analysis were considered, as well as the variable skin color due to relation described in other studies of the same nature. In the final multivariate model, variables with $p<0.05$ were considered and the best statistical adequacy of the final model was considered through the assessment of the log likelihood.

This research was approved by the Teaching and Research Commission of the Municipal Health Secretariat of Vitória da Conquista and later approved by the Research Ethics Committee of the Federal University of Bahia, under the number CAAE 58104116.8.0000.5556 and protocol number
1.736 .058 .

\section{Results}

Table 1 presents the descriptive analysis of the pregnant population included in the study $(\mathrm{n}=210)$.

In this study, it was verified that the age of the participants varied between 14 and 45 years, and the average age was approximately 27 years. Most pregnant women declared themselves as non-white, had 5 years or more of study, had a partner and reported family income below 2 minimum wages at the time of the research.

The collection of vaginal / rectal secretion occurred in pregnant women with an average of 34 weeks of pregnancy, occurring in almost half of them between 32 and 34 weeks. Regarding previous obstetric information, most women declared themselves to be multiparous with a number of previous pregnancies ranging from one to seven pregnancies. Previous miscarriage was reported by $15.2 \%(n=32)$ of pregnant women while $9.2 \%(n=11)$ of multiparous participants reported premature delivery. The use of antibiotics in the current pregnancy was reported by less than half of the pregnant women, with amoxicillin and cephalexin being the most cited by the pregnant women who used it.

The prevalence of colonization by GBS in pregnant women was of $18.1 \%(\mathrm{n}=38)$. Among them, $65.8 \%(\mathrm{n}=25)$ were between 27 and 45 years old, $50 \%(\mathrm{n}=19)$ were between 32 and 34 weeks of gestational age and $55.3 \%(\mathrm{n}=21)$ were primiparous. Among pregnant women colonized by GBS, $81.6 \%(\mathrm{n}=31)$ declared themselves as non-white, $89.5 \%(\mathrm{n}=34)$ had a partner and $65.8 \%(\mathrm{n}=25)$ revealed to have an income below 2 minimum wages. All colonized pregnant women had 5 years or more of study.

Table 1 also presents the univariate analysis where it was noticed that colonization by GBS was statistically associated $(p<0.05)$ with family income greater than or equal to 2 minimum wages, showing a 2.2 times chance of colonization by GBS compared to women with an income below 2 wages.

No statistically significant association was found between colonization by GBS and parity in the univariate analysis. However, when analyzing this variable in the group of older women ( 27 to 45 years old), it was observed that primiparous women in this group had 4.14 times the chance for colonization by GBS in relation to multiparous women $(p<0.05)$. In the group of younger women $(<27$ years) there was no statistically significant association between parity and colonization by GBS (Table 2). 
Table 1

Descriptive and univariate analysis of colonization by GBS in pregnant women from 32 to 40 weeks of gestation and selected variables.

\begin{tabular}{|c|c|c|c|c|}
\hline \multirow[t]{2}{*}{ Variables } & \multicolumn{4}{|c|}{ Colonization by GBS } \\
\hline & $\mathrm{N}$ & $\%$ & OR $(\mathrm{Cl} 195 \%)$ & $p$ \\
\hline \multicolumn{5}{|l|}{ Age group (years) } \\
\hline$<27$ & 102 & 48.6 & 1 & \\
\hline $27-45$ & 108 & 51.4 & $2.06(0.98-4.29)$ & 0.05 \\
\hline \multicolumn{5}{|l|}{ Skin color } \\
\hline White & 27 & 12.9 & $1.72(067-4.41)$ & 0.26 \\
\hline Non-white & 183 & 87.1 & 1 & \\
\hline \multicolumn{5}{|l|}{ Marital status** } \\
\hline Without partner & 25 & 12,0 & 1 & \\
\hline With partner & 184 & 88.0 & $1.19(0.38-3.69)$ & 0.76 \\
\hline \multicolumn{5}{|c|}{ Income ${ }^{* * *}$ (minimum wages) } \\
\hline$<2$ & 162 & 77.9 & 1 & \\
\hline$\geq 2$ & 46 & 22.1 & $2.2(0.97-4.66)$ & $0.04 *$ \\
\hline \multicolumn{5}{|c|}{ Gestational age (weeks) } \\
\hline $32-34$ & 100 & 47.6 & $0.92(0.44-1.92)$ & 0.83 \\
\hline $35-37$ & 84 & 40.0 & 1 & \\
\hline $38-40$ & 26 & 12.4 & $0.33(0.07-1.53)$ & 0.14 \\
\hline \multicolumn{5}{|l|}{ Parity** } \\
\hline Primiparous & 92 & 44.0 & $1.3(0.86-3.53)$ & 0.12 \\
\hline Multiparous & 117 & 56.0 & 1 & \\
\hline \multicolumn{5}{|l|}{ Previous miscarriage } \\
\hline Yes & 32 & 15.2 & 1 & \\
\hline No & 178 & 84.8 & $1.05(0.40-2.77)$ & 0.92 \\
\hline \multicolumn{5}{|l|}{ High blood pressure } \\
\hline Yes & 9 & 4.3 & 1 & \\
\hline No & 201 & 95.7 & $1.8(0.22-14.9)$ & 0.58 \\
\hline
\end{tabular}

*statistically significant association $<0.05 ; * * 1$ no reply; ***2 no reply; GBS= Group B Streptococcus.

Table 2

Univariate analysis of GBS colonization and age-stratified parity.

\begin{tabular}{|c|c|c|c|c|}
\hline \multirow[t]{3}{*}{ Variable } & \multicolumn{2}{|c|}{ Colonization by GBS } & \multicolumn{2}{|c|}{ Colonization by GBS } \\
\hline & \multicolumn{2}{|c|}{ Age $<27$ years } & \multicolumn{2}{|c|}{ Age between 27 and 45 years } \\
\hline & OR $(\mathrm{Cl} 95 \%)$ & $p$ & OR $(\mathrm{Cl} 195 \%)$ & $p$ \\
\hline \multicolumn{5}{|l|}{ Parity } \\
\hline Primiparous & 1 & & $4.14(1.6-10.7)$ & $0.002 *$ \\
\hline Multiparous & $0.96(0.29-3.19)$ & 0.95 & 1 & \\
\hline
\end{tabular}

*statistically significant association $<0.05 ; \mathrm{GBS}=$ Group B Streptococcus. 
The final model of the multivariate analysis (Table 3 ) revealed a statistically significant association between colonization by GBS and the variables age, color and parity. The association between income and colonization by GBS that had shown to be significant in the univariate analysis did not show any association in the multivariate analysis.

\section{Discussion}

The $18,1 \%$ prevalence of maternal colonization by GBS agrees with most national surveys. $8,12,15,16$ Regarding the anatomical sites of collection of clinical specimens for analysis, it is known that collection in the vaginal and rectal regions increases the sensitivity of the exam.17 The present study used this collection strategy (vaginal / anal), as well as carried out in the study by Borger et al.,18 which found a prevalence of $19.2 \%$. Diverging from the study by Linhares et al., 11 which pointed to a low frequency of colonization that was supposedly attri-buted to collection by a single swab.

Regarding the period of collection for GBS research, it is recommended that the culture should be performed in women with gestational period between 35 and 37 weeks. ${ }^{7}$ In this study samples were collected from pregnant women between 32 and 40 weeks, considering that colonization by GBS can increase the risk of spontaneous abortion and preterm labor. 3,19 In Campinas, high rates of maternal colonization in pregnant women with premature labor and premature rupture of the membrane were demonstrated. 20

In this study, pregnant women were categorized into three groups: 32 to 34 weeks, 35 to 37 weeks and 38 to 40 weeks. There was no statistically significant difference in colonization between these groups. This finding points to the need for investigation of GBS in different gestational periods than recommended, mainly due to situations of prematurity.

According to the literature, the prevalence of GBS varies according to the characteristics of the studied population. ${ }^{3}$ However, in Brazil, studies have not been convergent in associating colonization by GBS and sociodemographic or obstetric characteristics. $8,12,15,20$

Regarding the existence of an association between colonization by GBS and family income greater than or equal to two minimum wages, it was found in the final multivariate model that the association was statistically significant for age and not for family income. This occurred in the present investigation, since women under the age of 27 also had a lower income, and thus, age was a confounding variable in the univariate analysis. After the final adjust-

Table 3

Final logistic regression model by group of selected variables and colonization by GBS.

\begin{tabular}{|c|c|c|}
\hline \multirow[t]{2}{*}{ Variables } & \multicolumn{2}{|c|}{ Colonization by GBS } \\
\hline & OR $(\mathrm{Cl} 95 \%)$ & $p$ \\
\hline \multicolumn{3}{|c|}{ Age group (years) } \\
\hline$<27$ & 1 & \\
\hline $27-45$ & $0.4(0.18-0.93)$ & $0.03 *$ \\
\hline \multicolumn{3}{|l|}{ Skin color } \\
\hline White & 1 & \\
\hline Non-white & $3.19(1.13-9.02)$ & $0.03 *$ \\
\hline \multicolumn{3}{|c|}{ Income $^{2}$ (minimum wages) } \\
\hline$<2$ & 1 & \\
\hline$\geq 2$ & $0.55(0.23-1.28)$ & 0.17 \\
\hline \multicolumn{3}{|c|}{ Gestational age (weeks) } \\
\hline $32-34$ & 1 & \\
\hline $35-37$ & $0.74(0.33-1.65)$ & 0.48 \\
\hline $38-40$ & $3.05(0.61-15.3)$ & 0.17 \\
\hline \multicolumn{3}{|l|}{ Parity } \\
\hline Primiparous & $0.34(0.15-0.78)$ & $0.01 *$ \\
\hline Multiparous & 1 & \\
\hline
\end{tabular}

*statistically significant association <0.05; Log likelihood initial model = 183.37; Log likelihood final model = 178.56 . GBS $=$ Group B Streptococcus. 
ment, it was found that women with maternal age between 27 and 45 years had a $60 \%$ lower chance of being colonized by GBS when compared to pregnant women under 27 years $(p<0.05)$.

The association between parity and colonization was significant $(p<0.05)$ in univariate and multivariate analyzes. When analyzing parity in the group of women aged 27 to 45 , primiparous pregnant women had a 4.14-fold chance of colonization by GBS, when compared to multiparous women $(p<0.05)$. In Florianópolis, age and parity were assessed together and the older the age group, the risk of colonization among primiparous women increased.10As for the United States, older women with low parity are at greater risk of being colonized by GBS. 3

In the multivariate analysis, it was demonstrated that being primiparous is a protective factor $(\mathrm{OR}=$ $0.34)$ when compared to multiparous in the total sample of the study $(p<0.05)$. Thus, primiparous pregnant women had a $66 \%$ lower chance of colonization by GBS compared to multiparous women. Corroborating to this relationship, in India, in a study with low socioeconomic level participants, the colonization rate by GBS was significantly higher among multiparous women than among primiparous women. 21

It was also found that black skin color was associated with a greater chance of colonization by GBS. The multivariate analysis showed that non-white women had 2.19 times the chance for colonization by GBS compared to white women $(p<0.05)$. These findings agree with results found in Ceará and Santa Catarina.11,22 However, the results related to skin color / race should be interpreted with caution due to the miscegenation of the Brazilian people, and there may be no consensus regarding this variable, such as Nomura et al., ${ }^{20}$ who found white color associated with colonization in Campinas in the univariate analysis.

In this study, schooling was not an explanatory variable associated with colonization by GBS. This probably occurred due to the homogeneity in relation to the studied population composed of women with 5 years or more of study. The findings found in this and other studies indicate that, despite the literature pointing out some risk factors for maternal colonization by GBS, the results have shown to be inconsistent in several studies, and it is not possible to select a group of women with a high probability of being colonized. It should be emphasized that GBS research must be carried out in all pregnant women and not only in those who present risk factors. $3,10,15$ When maternal colonization rates exceed $10 \%$, universal screening programs are cost-effective. ${ }^{23}$ For the strategy of carrying out cultures in pregnant women in the present study, the cost for tracking GBS was estimated at R\$ 18.00 per pregnant woman, with a sensitivity of $96.9 \%$ for detecting GBS. ${ }^{24}$ This value was stipulated, based on the use of a swab with Stuart transport medium for the collection of biological sample, which would be inoculated in the Todd-Hewitt medium and transferred to a chromogenic agar plate, and took into account the expenses with the realization of antibiogram for positive samples. Thus, the annual cost for screening, estimating a number of births in Vitória da Conquista per year being around 5 thousand, would be around $\mathrm{R} \$ 90$ thousand.

Considering this average annual births and the colonization rate in pregnant women found in the municipality of $18.1 \%, 905$ pregnant women would be colonized by GBS. Thus, assuming that up to $2 \%$ of newborns from colonized parturients will develop the invasive disease of early onset, it can be estimated that approximately 18 newborns each year will require hospitalization, including in intensive care units (ICU). Based on the work of Desgualdo et $a l ., 25$ the costs involved with these hospitalizations would reach approximately R \$ 132 thousand.

Despite the limitations involved in the cost calculations in this study, such as the unavailability of current data on hospital expenses for infected newborns in the municipality studied, the findings reveal that the screening of pregnant women in the municipality is a cost-effective strategy when considered the high costs of hospitalization of newborns, parental leave from work and mental illness due to the hospital stay. Furthermore, it is necessary to consider that, by adopting a prevention strategy, it is possible to decrease and even avoid neonatal morbidity and mortality resulting from infection by GBS and hospital beds, including neonatal ICUs.

This study showed a clear need to implement an intervention strategy aimed at improving prenatal care and neonatal health conditions in the municipality of Vitória da Conquista. The data found showed an important prevalence of maternal colonization by GBS in the municipality, and some risk factors associated with colonization, similar to studies carried out in different regions of the country. Regarding the gestational age for collection, it is suggested that other studies should be carried out to assess the colonization of pregnant women in gestational periods, considering the need for also evaluating the situations of prematurity. 


\section{Authors' contribution}

All authors contributed equally in all stages of the paper. The final version was approved by all the authors.

\section{References}

1. Winn Jr. W, Allen S, Janda W, Procop G, Schreckenberge P, Woods G. Koneman Diagnóstico Microbiológico. 6 ed. Rio de Janeiro: Guanabara Koogan; 2008.

2. Areal A, Nunes S, Moreira M, Faustino MA, Cardoso L, As C. Infecção perinatal por Streptococcus agalactiae pode ser evitada: Prevalência da colonização em parturientes no Hospital São Marcos, factores de risco e a sua relação com a infecção perinatal. Acta Pediatr Port. 2010; 41 (1): 16-21.

3. Regan JA, Klebanoff MA, \& Nugent RP. The epidemiology of group B streptococcal colonization in pregnancy. Vaginal Infections and Prematurity Study Group. Obstetr Gynecol. 1991; 77 (4): 604-10.

4. Gotoff SP. Group B streptococcal infections. Pediatr Rev. 2002; 23 (11): 381-6.

5. Heath PT, Balfour G, Weisner AM, Efstratiou A, Lamagn TL, Tighe H, Connell LAF, Cafferkey M, Verlander NO Nicoll A, McCartney AC. Group B streptococcal disease in UK and Irish infants younger than 90 days. Lancet. 2004; 363 (9405): 292-4

6. Baker CJ, Edwards MS. Group B streptococcal infections. IN: Remington J, Klein JO, eds. Infectious Diseases of the Fetus and Newborn Infant. 4th ed. Philadelphia, PA: WB Saunders Co; 980-1054; 1995.

7. Centers for Disease Control and Prevention (CDC). Prevention of Perinatal Group B Streptococcal Disease: revised Guidelines from CDC. MMWR Morb Mortal Wkly Rep. 2010; 59 (10): 1-23.

8. Costa ALR, Lamy Filho F, Chein MBC, Brito LMO, Lamy ZC, Andrade KL. Prevalência de colonização por estreptococos do grupo B em gestantes atendidas em maternidade pública da região Nordeste do Brasil. Rev Bras Ginecol Obstet. 2008; 30 (6): 274-80.

9. Amaral E. Estreptococo do grupo B: rastrear ou não rastrear no Brasil? Eis a questão. RBGO. 2005; 27 (4): 165-7.

10. Pogere A, Zoccoli CM, Tobouti NR, Freitas PF, d'Acampora AJ, Zunino JN. Prevalência da colonização pelo estreptococo do grupo B em gestantes atendidas em ambulatório de pré-natal. Rev Bras Ginecol Obstet. 2005; 27 (4): 174-80.

11. Linhares JJ, Neto PGC, Vasconcelos JL, Saraiva TV, Ribeiro AMF, Siqueira TM, Rocha AF. Prevalência de colo- nização por Streptococcus agalactiae em gestantes atendidas em maternidade do Ceará, no Brasil, correlacionando com os resultados perinatais. Rev Bras Ginecol Obstetr. 2011; 33 (12):395-400.

12. Melo SCCSD, Costa AB, Silva FTRD, Silva NMMG, Tashima CM, Cardoso RF, Pádua RAF, Previdelli I, Carvalho MDB, Pelloso SM. Prevalence of Streptococcus agalactiae colonization in pregnant women from the 18th Health Region of Paraná State. Rev Inst Med Trop São Paulo. 2018; 60: e1-e6.

13. Oliveira MV, Teles MF, Viana TA. Prevalência e fatores de risco associados à colonização por Streptococcus agalactiae em gestantes atendidas no Hospital Municipal Esaú Matos em Vitória da Conquista-BA. Ciênc Desenvolv Rev Eletr FAINOR. 2013; 6 (1): 172-84.

14. Borger IL. Estudo da colonização por Streptococcus agalactiae em gestantes atendidas na maternidade escola da Universidade Federal do Rio de Janeiro [dissertação]. Rio de Janeiro: Universidade Federal do Rio de Janeiro; 2005.

15. Senger FR, Alves IA, Pellegrini DDCP, Prestes DC, de Souza EF, Dalla Corte E. Prevalência da colonização por Streptococcus agalactiae em gestantes atendidas na rede pública de saúde de Santo Ângelo-RS. Rev Epidemiol Controle Infecç. 2016; 6 (1): 1-5.

16. Beraldo C, Brito ASJ, Saridakis HO, Matsuo T. Prevalência da colonização vaginal e anorretal por estreptococo do grupo B em gestantes do terceiro trimestre. RBGO. 2004; 26 (7): $543-9$

17. Schrag S, Gorwitz R, Fultz-Butts K, Schuchat A Prevention of perinatal group $\mathrm{B}$ streptococcal disease. Revised guidelines from CDC. MMWR Recomm Rep 2002; 51 (RR-11): 1-22

18. Borger IL, D'Oliveira REC, Castro ACD, Mondino SSB. Streptococcus agalactiae em gestantes: prevalência de colonização e avaliação da suscetibilidade aos antimicrobianos. Rev Bras Ginecol Obstet. 2005; 27 (10): 575-9.

19. Regan JA, Klebanoff MA, Nugent RP, Eschenbach DA, Blackwelder WC, Lou Y, Gibbs RS, Rettig PJ, Martin DH, Edelman R. Colonization with group B streptococci in pregnancy and adverse outcome. Am J Obstet Gynecol. 1996; 174 (4): 1354-60. 
20. Nomura ML, Passini Júnior R, Oliveira UM, Calil R. Group $\mathrm{B}$ streptococcus maternal and neonatal colonization in preterm rupture of membranes and preterm labor. Rev Bras Ginecol Obstet. 2009; 31 (8): 397-403.

21. Orrett FA. Colonization with Group B streptococci in pregnancy and outcome of infected neonates in Trinidad. Pediatr Int. 2003; 45 (3): 319-23

22. Kruk CR, Feuerschuette OHM, Silveira SKD, Cordazo M, Trapani Júnior A. Epidemiologic profile of Streptococcus agalactiae colonization in pregnant women attending prenatal care in a city of southern of Brazil. Braz J Infect Dis. $2013 ; 17$ (6): 722-3.

23. Strickland DM, Yeomans ER, Hankins GD. Cost-effectiveness of intrapartum screening and treatment for maternal group B streptococci colonization. Am J Obstet Gynecol 1990; 163 (1): 4-8
24. Santana FAF. Comparação de metodologias de identificação, perfil de susceptibilidade antimicrobiana e determinação de genes de resistência em cepas de Streptococcus agalactiae isoladas de gestantes de Vitória da Conquista BA [dissertação]. Vitória da Conquista: Universidade Federal da Bahia; 2018.

25. Desgualdo CM, Riera R, Zucchi P. Estimativa de custo de internação hospitalar para recém nascidos prematuros em um hospital publico terciário no Brasil. Clinics. 2011; 66 (10): 1773-7.

Received on October 6, 2019

Final version presented on July 20, 2020

Approved on August 27, 2020 